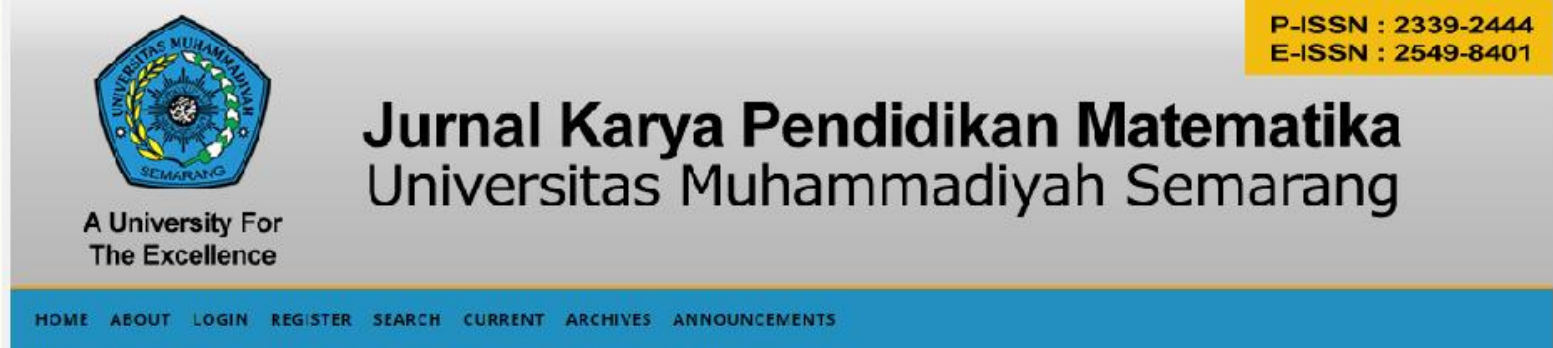

\title{
ANALISIS FAKTOR PRIORITAS MAHASISWA DALAM MEMILIH JURUSAN DENGAN FUZZY ANALITIC HIERARCHY PROCESS
}

\author{
Benny Sofyan Samosir ${ }^{1}$, Wiwik Novitasari ${ }^{2}$, Safran Efendi Pasaribu ${ }^{3}$ \\ ${ }^{(1,2,3)}$ Dosen Universitas Muhammadiyah Tapanuli Selatan
}

\begin{tabular}{ll}
\hline \multicolumn{2}{l}{ Article history } \\
\hline Submission & $: 18 / 7 / 2018$ \\
Revised & $:-$ \\
Accepted & $: 20 / 8 / 2018$
\end{tabular}

Keyword:

Private University, Study

Program, Fuzzy

Hierarchy process

Analysis

\begin{abstract}
University is the institution engaged in public service namely education services needs to identify the student candidates on education product, develops educational products and implements marketing activities to attract the attention of the student candidates. The purpose of this study is to determine priority consideration for students in choosing a study program at the College. The method used in this study is Fuzzy Analysis Hierarchy Process (FAHP), with the results of the study, the order's rank criteria factor (Study Program profile, Infrastructure, The Activity of study Program and Rules of Conduct), the rank order of the sub factor infrastructure criteria (Quality of College Building, Library, Sport Facilities, Laboratory), the order of subcriteria rank factor of study Program profile ( lay out and Accreditation of study program, the length of the Study, Graduates Lecturer), a sequence of sub criteria ranking factors study program of activities (Seminar, Community Service, fieldtrip, Research), and the sequence of sub-criteria rank factor of the order of (Lectures, students number, Clothing, Leaves).
\end{abstract}

\section{Pendahuluan}

Kita tidak dapat memungkiri bahwa manusia memiliki keterkaitan yang erat dengan pendidikan, dengan pengertian luas pendidikan adalah segala aktifitas dalam kehidupan yang memiliki pengaruh perkembangan individu sebagai pengalaman belajar yang berlangsung diseluruh lingkungannya dan selama kehidupan manusia itu berlangsung. Pendidikan juga merupakan suatu bentuk perjuangan setiap manusia agar dapat memperbesar potensi yang terdapat dalam dirinya melalui tahapan - 
tahapan pembelajaran yang dialaminya selama kehidupannya berlangsung.

Perguruan tinggi adalah salah satu diantara sekian banyak lembaga penyelenggaraan yang juga pengembang pendidikan yang memiliki fungsi utamanya meningkatkan kualitas kehidupan masyarakat, bangsa juga negara. Pada perguruan tinggi, kegiatan pendidikan yang ditempuh difokuskan pada satu bidang konsentrasi keilmuan yang diminati dengan tujuan agar dapat fokus mengembangkan potensi diri sesuai dengan dunia kerja yang diminati. Kebutuhan masyarakat luas utamanya para generasi muda dalam menggapai kesuksesan berkarir serta menyiasati persaingan yang ketat pada dunia kerja, merupakan salah satu faktor pendukung munculnya begitu banyak jumlah perguruan tinggi yang menyebar di negara ini, serta faktor itu jugalah mungkin yang mendukung munculnya jenis jenis perguran tinggi yang menawarkan berbagai konsentrasi bidang ilmu di negara ini.

Perguruan tinggi swasta adalah pilihan alternative bagi masyarakat yang berkeinginan kuat untuk mengeyam pendidikan pada jenjang perguruan tinggi namun memiliki nasib yang kurang beruntung lulus pada proses seleksi di perguruan tinggi negeri, Jumlah perguruan tinggi swasta utamanya di Negara ini yakni indonesia berjumlah cukup besar. Hal ini mengakibatkan persaingan yang kuat antar perguruan tinggi swasta dalam menarik minat calon mahasiswa untuk mendaftar di kampus yang dioperasikan oleh masing masing penyelenggara.

Perguruan tinggi swasta juga merupakan salah satu diantara sekian banyak pemasar pendidikan yang juga penting memberlakukan kegiatan mengidentifikasi calon mahasiswa terhadap produk ruang lingkup pendidikan. meningkatkan produk ruang lingkup pendidikan dan memberlakukan promosi untuk menarik perhatian dan memberi tanggapan yang erat dari calon mahasiswa. Kelebihan perguruan tinggi swasta dalam hal menarik minat calon mahasiswa semakin ditingkatkan. Baik itu dari sisi prestasi, sisi tampilan fisik, hingga dari sisi fasilitas yang akan dipergunakan oleh calon mahasiswa. Perguruan tinggi swasta adalah salah satu jenis perusahaan penyedia layanan jasa yang bergerak dibidang jasa pendidikan. Dimasa sekarang ini dengan banyaknya lahir perguruan tinggi swasta, dirasa penting mengetahui standar perguruan tinggi yang berkualitas. Penawaran pelayanan jasa perguruan tinggi kepada masyarakat luas khusunya generasi muda di negeri ini semakin beraneka ragam, yang mengakibatkan persaingan antar perguruan tinggi sawasta dalam memikat calon mahasiswa semakin ketat.

Mahasiswa merupakan sumber daya yang begitu penting pada Perguruan Tinggi. Semakin besar jumlah mahasiswa pada perguruan tinggi identiknya linier dengan peningkatan mutu serta kepercayaan dari publik pada lembaga itu. Dilain sisi, lahirnya mahasiswa pada perguruan tinggi juga menjadi faktor penentu sumber pendanaan pada perguruan tinggi tersebut guna biaya operasional, terlebih perguruan tingginya adalah perguruan tinggi swasta yang mana sumber operasional kampus tersebut tidak ditanggung oleh negara seperti perguruan tinggi negeri pada umumnya.

Calon mahasiswa baru dalam hal memilih konsentrasi bidang keilmuan/ program studi di jenjang perguruan tinggi tentunya memiliki kriteria kriteria atau faktor faktor penilaian yang berkaitan dengan bidang keilmuan yang akan dipilih pada target kampus pilihannya. Informasi kampus serta program studi identiknya dicari dari berbagai referensi / sumber, diantaranya situs web kampus yang menjadi target pilihan calon mahasiswa, koran, spanduk, orang tua, temannya sendiri, dan sebagainya. Informasi yang dicari oleh calon mahasiswa diantaranya tentang lokasi kampus, sarana prasarana, kegiatan kemahasiswaan, tata tertib, akreditasi, lama waktu kuliah,dll pada konsentrasi bidang ilmu / program studi yang akan dipilih. Beranjak dari pemikiran seperti itulah maka dianggap perlu mengadakan penelitian tentang faktor- faktor pengambilan / penarikan kebijakan keputusan dari calon mahasiswa dalam memilih konsentrasi bidang keilmuan pada kampus yang menjadi target pilihannya, guna melihat faktor - faktor mana sebenarnya yang memiliki korelasi tererat yang menjadi faktor penilaian bagi calon mahasiswa dalam menentukan pilihan kampus / program studi sehingga perguruan tinggi swasta tidak mengalami kegagalan dalam pembangunan kampusnya sehingga bisa fokus dalam 
pembangunan yang berkaitan dengan faktor faktor yang menjadi indikator penilaian para calon mahasiswa dalam memilih perguruan tinggi swasta.

Faktor pendukung pengambilan keputusan untuk membeli salah satu produk dipengaruhi oleh faktor perbedaan individu, pengaruh lingkungan dan proses psikologis. Faktor - factor ini berguna untuk pengendali pasar guna mengidentifikasi para pembeli potensial terhadap suatu produk, meningkatkan produk serta menerapkan promosi untuk menarik minat para konsumen (Umar, Riset Pemasatan Perilaku Konsumen, 2003). Merujuk dari kutipan ini Perguruan Tinggi, harus mampu mengetahui factor faktor penentu keputusan dari para generasi muda khususnya calon mahasiswa/i agar memilih perguruan tinggi yang sesuai dengan pilihan minat ( jurusan ) calon mahasiswa/i tersebut

Beranjak dari latar belakang yang telah dipaparkan di atas, peneliti merumuskan permasalahan dalam penelitian ini dengan lebih menitik beratkan pada "Analisis Faktor Prioritas Mahasiswa Dalam Memilih Jurusan di Kota Padangsidimpuan Dengan Fuzzy Analitic Hierarchy Process ?"

Penelitian ini bertujuan untuk mendapatkan informasi mengenai faktor Prioritas yang menjadi pertimbangan kebijakan penentuan pilihan bagi mahasiswa dalam memilih konsentrasi bidang keilmuan / Program Studi pada Perguruan Tinggi Swasta di wilayah kota padangsidimpuan. Yang diharapkan dapat menjadi masukan bagi pengelola penyedia layanan jasa dalam hal ini bidang pendidikan Perguruan Tinggi Swasta untuk memantapkan strategi pemasarannya dengan merujuk dari hasil Penelitian ini.

manfaat yang dapat diperoleh dari penelitian ini:

1. Secara teoritis, penelitian ini berguna untuk memperbanyak referensi penelitian tentang faktor - faktor yang berhubungan dengan teori kebijakan pengambilan keputusan dan strategi pemasaran pada usaha yang bergerak dibidang pelayanan jasa dalam hal ini lebih focus membahas pelayanan jasa dalam bidang pendidikan .

2. Secara akademis, penelitian ini dapat disumbangkan kepada Perguruan Tinggi, khususnya Perguruan Tinggi Swasta, dalam rangka menambah rujukan bahan pertimbangan bagi pihak pengelola/ manajemen dalam menentukan strategi pemasaran perguruan tinggi / Program Studi.

3. Secara praktis, sebagai sumbang pemikiran dan saran kepada pembaca dan nantinya dapat digunakan sebagai referensi pada penelitian penelitian selanjutnya.

\section{Analytic Hierarchy Process}

Analytic Hierarchy Process (AHP) merupakan salah satu dari sekian banyak pilihan metode yang mampu menyelesaikan permasalahan permasalahan berwujud Multi Criteria Decision Making yang dipelopori oleh seorang Ahli dalam dunia Matematika bernama Thomas Lorie Saaty sering juga di tulis Thomas L.Saaty. Analytic Hierarchy Process (AHP) sering digunakan dalam penelitian - penelitian yang berkaitan dengan sifat manusia, analisis pemikiran serta pengukuran yang berguna dalam menyelesaikan permasalahan kualitatif atau kuantitatif. Analytic Hierarchy Process (AHP) merupakan metode yang memiliki sifat luwes, saat digunakan menyelesaikan permasalahan, Analytic Hierarchy Process (AHP) memberikan pertimbangan berupa intuitif selain pertimbangan ilmiah yang dapat menampung sifat alamiah manusia dibanding metode lain yang terkadang bersifat memaksa responden dalam cara berfikir yang justru berlawanan dengan nurani si responden dalam penelitian.

Landasan aksiomatik dari Analytical Hierarchy Process (AHP) terdiri dari :

a. Reciprocal Comparison, yang berarti matriks perbandingan berpasangan yang terbentuk harus bersifat berkebalikan.

b.Homogenity, yang berarti membandingkan atau memberikan penilaian pada sesuatu hal yang sama.

c.Dependence, yang berarti setiap level mempunyai hubungan satu sama lain dengan level lainniya

d.Expectation, yang berarti mengedepankan penilaian yang sifatnya ekspektasi serta preferensi dari pengambilan keputusan.

Saat melakukan penilaian kerap terjadi ketidak konsistensian pemikiran ataupun 
penialaian dari responden, pada metode Analisis Hierarki Proses hal ini menjadi sesuatu hal yang perlu untuk diperhatikan. Oleh sebab itu Thomas L Saaty dalam metode yang membesarkan namanya ini mengevaluasi dan memberlakukan nilai konsistensi, nilai ini di dapat dengan menggunakan formula

$$
C I=\frac{\left(\lambda_{\max }-n\right.}{(n-1)} \ldots
$$

Selanjutnya menentukan nilai batasan ketidak konsistenan, dimana menenetukan nilainya dengan menggunakan perbandingan nilai rasio konsistensi $(C R)$ menggunakan formula

$$
C R=\frac{C I}{R I} \ldots
$$

\section{Fuzzy Analisis Hierarki Proses}

Metode Fuzzy Analisis Hierarki Proses merupakan suatu metode analisis yang dikembangkan dari Analisis Hierarki Proses, Metode Fuzzy Analisis Hierarki Proses (FAHP) pertama kali diusulkan oleh seroang peneliti bernama Chang yang memiliki tujuan serta pemikiran meskipun Analisis Hierarki Proses biasa digunakan dalam menangani kriteria kualitatif dan kuantitatif namun Fuzzy Analisis Hierarki Proses dianggap lebih baik dalam mendeskripsikan keputusan yang sifatnya samar-samar dibanding Analisis Hierarki Proses, ini dikarenakan kita tidak dapat memungkiri dalam kehidupan sehari hari sering dihadapkan dengan situasi demikian dalam memberi keputusan pada permasalah permasalahan hidup. (Lu J, Zang, 2007)

Metode Fuzzy menggunakan ratio fuzzy yang sering diistilahkan dengan sebutan Tringular Fuzzy Number dan Ratio Fuzzy ini biasa dipergunakan dalam proses Fuzzyfikasi pada metode ini. Tringular Fuzzy Number ini berasal dari tiga unsur fungsi keanggotaan yang mana nilai terendah disebut dengan Low disinggkat (L) nilai tengah disebut Medium disingkat (M) serta nilai tertinggi disebut Upper disingkat (U). (Anshori yusuf, 2012)

\section{Tahapan - Tahapan Fuzzy Analisis Hierarki Proses}

Langkah - langkah pengerjaan metode Fuzzy Analisi Hierarki Proses sebagai berikut:

1. Membuat struktur hierarki masalah yang akan diselesaikan dan menentukan perbandingan matriks berpasangan antar kriteria dengan skala Tringular Fuzzy Number (TFN)

2.Menentukan nilai sistesis fuzzy (Si) prioritas dengan menggunakan formula:

$$
S_{i}=\sum_{j=i}^{m} M_{i}^{j} x \frac{1}{\sum_{i=1}^{n} \sum_{j=1}^{m} M_{i}^{j}} \ldots
$$

Dimana:

$$
\sum_{j=1}^{m} M_{i}^{j}=\sum_{j=1}^{m} l_{j}, \sum_{j=1}^{m} m_{i}^{j}, \sum_{j=1}^{m} u^{j} \ldots
$$

3. Menentukan nilai vektor (V) dan nilai Ordinat Defuzzifikasi (d) jika hasil yang didapat pada setiap matrik fuzzy, $M_{2} \geq$ $M_{1}\left(M_{2}=l_{2}, m_{2}, u_{2}\right.$ dan $M_{2}=\left(l_{1}, m_{1}, u_{1}\right)$ sehingga nilai vector dapat di rumuskan sebagai berikut :

$$
\begin{aligned}
& V\left(M_{2} \geq M_{1}\right) \\
& =\sup \left[\min \left(\mu M_{1}(x), \min \left(\mu M_{2}(y)\right)\right)\right] \ldots(6)
\end{aligned}
$$

4. Normalisasi nilai bobot vektor fuzzy $(W)$ setelah dilakukan normalisasi dari persamaan didapat Nilai bobot vektor yang ternormalisasi menggunakan rumus berikut:

(Chang 1996)

$$
W\left(d\left(A_{1}\right), d\left(A_{2}\right), \ldots, d\left(A_{n}\right) T \ldots(7)\right.
$$

\section{Penelitian Terdahulu}

Doraid dalalah (2010) dalam penelitiannya yang berjudul Aplication of the analytic hierarchy process (AHP) in Multi Criteria Analysis of the selection of cranes menyatakan Analitic hierarchy process mampu memberikan solusi pada pengambilan keputusan pemilihan jenis crane untuk bidang kerja konstruksi. Pada penelitiannya doraid dalalah (2010) menuliskan dengan menggunakan skala lisan membuat pengambilan keputusan lebih mudah dalam 
pemberian bobot penilaian dalam kasus yang diteliti.

Wahyudi Setiawan (2015) pada penelitiannya yang berjudul penerapan metode Fuzzy Analytical Hierarchy Process untuk pemilihan supplier batik madura menyatakan supplier dipilih berdasarkan pada kriteria kriteria yang telah ditetapkan perusahaan. Pemilihan suppilier penting dilakukan dengan tujuan meminimalkan biaya pengeluaran dan meningkatkan daya saing. Untuk memilih supplier pemenang digunakan metode Fuzzy Analytical Hierarchy Process karena dianggap lebih bagus dalam pengambilan keputusan.

Rouyendegh (2012) menggunakan metode Fuzzy Analytic Hierarchy Process, pada penelitiannya yang berjudul Selection Of Academic Staff Using The Fuzzy Analitic Hierarchy Process__Rouyendegh (2012) menyatakan bahwa, masalah yang dihadapi dalam proses seleksi staff akademik merupakan masalah yang erat kaitannya dngan penialaian tidak mutlak, dalam penelitian rouyendegh (2012) menggunakan pembobotan dengan metode Tringular Fuzzy Number.

Nurma Agus Sari (2014) dengan judul penelitian " Sistem Pendukung Keputusan Pemilihan Mahasiswa Berprestasi Menggunakan Metode Analytical Hierarchy Process (AHP)" penelitian ini bertujuan untuk untuk menentukan mahasiswa yang pantas diberi penghargaan sebagai Mahasiswa Berprestasi dan berhak mengikuti pemilihan mahasiswa berprestasi di tingkat nasional.

Antono Adhi (2010) dengan judul penelitian "Pengambilan Keputusan Pemilihan Handphone Terbaik Dengan Analytical Hierarchy Process (Ahp)" penelitian ini bertujuan untuk dapat mengambil keputusan dalam penentuan handphone terbaik dari tiga alternatif merek handphone dengan beberapa kriteria melalui metode Analytical Hierarchy Process (AHP).

\section{Metode Penelitian}

Penelitian ini merupakan penelitian yang mencerminkan penelitian bersifat deskriptif. dalam analisis data penelitian ini Peneliti menggunakan Metode Fuzzy Analytic Hierarchy Process (FAHP). Data yang dipergunakan pada penelitian ini merupakan data berjenis primer dimana peneliti mendapatkan informasi tentang data yang dibutuhkan dalam penelitian ini secara langsung bertemu dengan responden yang menjadi sampel pada penelitian ini. (Suryano,2008).

\section{Hasil Penelitian dan Pembahasan}

a. Matriks perbandingan berpasangan
antar criteria

\begin{tabular}{|c|c|c|c|c|}
\hline & $\begin{array}{l}\text { Sarana } \\
\text { prasara } \\
\text { na }\end{array}$ & $\begin{array}{l}\text { Profil } \\
\text { Prodi }\end{array}$ & $\begin{array}{l}\text { Kegi } \\
\text { atan } \\
\text { Prodi }\end{array}$ & $\begin{array}{l}\text { Tata } \\
\text { terti } \\
\text { b }\end{array}$ \\
\hline $\begin{array}{l}\text { Sarana } \\
\text { Prasara } \\
\text { na }\end{array}$ & 111 & 113 & 468 & $\begin{array}{l}35 \\
7\end{array}$ \\
\hline $\begin{array}{l}\text { Profil } \\
\text { Prodi } \\
\end{array}$ & $\begin{array}{l}1 / 3 \quad 1 / 1 \\
1 / 1\end{array}$ & 111 & 579 & $\begin{array}{l}35 \\
7 \\
\end{array}$ \\
\hline $\begin{array}{l}\text { Kegiat } \\
\text { an } \\
\text { Prodi }\end{array}$ & $\begin{array}{l}1 / 81 / 6 \\
1 / 4\end{array}$ & $\begin{array}{l}1 / 9 \\
1 / 7 \\
1 / 5\end{array}$ & 111 & $\begin{array}{l}12 \\
4\end{array}$ \\
\hline $\begin{array}{l}\text { Tata } \\
\text { tertib }\end{array}$ & $\begin{array}{l}1 / 71 / 5 \\
1 / 3\end{array}$ & $\begin{array}{l}1 / 7 \\
1 / 5 \\
1 / 3\end{array}$ & $\begin{array}{l}1 / 4 \\
1 / 2 \\
1 / 1\end{array}$ & $\begin{array}{l}11 \\
1\end{array}$ \\
\hline
\end{tabular}

Nilai sintesis fuzzynya

\begin{tabular}{|l|l|l|l|}
\hline & L & M & U \\
\hline S1 & 0.199 & 0.403 & 0.860 \\
\hline S2 & 0.206 & 0.434 & 0.814 \\
\hline S3 & 0.049 & 0.102 & 0.246 \\
\hline S4 & 0.033 & 0.059 & 0.120 \\
\hline
\end{tabular}

bobot kriteria berturut turut sebagai berikut : $0.582,0.526,0.055,-0.164$ ( Profil Prodi, Sarana Prasarana, Kegiatan Prodi, Tata Tertib).

b.Matriks perbandingan berpasangan antar sub kriteria sarana prasarana

\begin{tabular}{|c|c|c|c|c|}
\hline & $\begin{array}{l}\text { Mut } \\
\text { u } \\
\text { Ged } \\
\text { ung }\end{array}$ & $\begin{array}{l}\text { Perpust } \\
\text { akaan }\end{array}$ & $\begin{array}{l}\text { Laborat } \\
\text { orium }\end{array}$ & $\begin{array}{l}\text { Sar } \\
\text { ana } \\
\text { Ola } \\
\text { h } \\
\text { Rag } \\
\text { a }\end{array}$ \\
\hline $\begin{array}{l}\text { Mutu } \\
\text { Gedung }\end{array}$ & $\begin{array}{l}11 \\
1 \\
\end{array}$ & 124 & 357 & $\begin{array}{l}13 \\
5\end{array}$ \\
\hline $\begin{array}{l}\text { Perpust } \\
\text { akaan }\end{array}$ & $\begin{array}{l}1 / 4 \\
1 / 2 \\
1 / 1\end{array}$ & 111 & 135 & $\begin{array}{l}11 \\
3\end{array}$ \\
\hline $\begin{array}{l}\text { Laborat } \\
\text { orium }\end{array}$ & $\begin{array}{l}1 / 7 \\
1 / 5 \\
1 / 3\end{array}$ & $\begin{array}{l}1 / 51 / 3 \\
1 / 1\end{array}$ & 111 & $\begin{array}{l}12 \\
4\end{array}$ \\
\hline $\begin{array}{l}\text { Sarana } \\
\text { Olah }\end{array}$ & $\begin{array}{l}1 / 5 \\
1 / 3\end{array}$ & $\begin{array}{l}1 / 3 \quad 1 / 1 \\
1 / 1\end{array}$ & $\begin{array}{l}1 / 41 / 2 \\
1 / 1\end{array}$ & $\begin{array}{l}11 \\
1\end{array}$ \\
\hline
\end{tabular}


Jurnal Karya Pendidikan Matematika Vol 5 No 2 (2018) E ISSN : 2549 - 8401 P ISSN : 2339-2444

\section{\begin{tabular}{l|l} 
Raga & $1 / 1$
\end{tabular}}

Nilai sintesis fuzzynya

\begin{tabular}{|l|l|l|l|}
\hline & L & M & U \\
\hline S1 & 0.160 & 0.481 & 1.271 \\
\hline S2 & 0.087 & 0.240 & 0.747 \\
\hline S3 & 0.062 & 0.154 & 0.473 \\
\hline S4 & 0.047 & 0.123 & 0.299 \\
\hline
\end{tabular}

bobot Sub Kriteria sarana prasarana berturut turut sebagai berikut : $0.71,0.40,0.15,-0.27$ ( Mutu Gedung Kuliah, Perpustakaan, Sarana Olah Raga, Laboratorium).

c. Matriks perbandingan berpasangan antar sub kriteria profil prodi

\begin{tabular}{|c|c|c|c|c|}
\hline & $\begin{array}{l}\text { Lam } \\
\text { a } \\
\text { Stud } \\
\text { i }\end{array}$ & $\begin{array}{l}\text { Lulus } \\
\text { an } \\
\text { Dosen }\end{array}$ & $\begin{array}{l}\text { Akredit } \\
\text { asi } \\
\text { Prodi }\end{array}$ & $\begin{array}{l}\text { Leta } \\
\mathrm{k} \\
\text { Pro } \\
\text { di }\end{array}$ \\
\hline $\begin{array}{l}\text { Lama } \\
\text { Studi }\end{array}$ & $\begin{array}{l}11 \\
1\end{array}$ & 357 & $\begin{array}{l}1 / 51 / 3 \\
1 / 1\end{array}$ & $\begin{array}{l}1 / 6 \\
1 / 4 \\
1 / 2\end{array}$ \\
\hline $\begin{array}{l}\text { Lulusan } \\
\text { Dosen }\end{array}$ & $\begin{array}{l}1 / 7 \\
1 / 5 \\
1 / 3\end{array}$ & 111 & $\begin{array}{l}1 / 71 / 5 \\
1 / 3\end{array}$ & $\begin{array}{l}1 / 8 \\
1 / 6 \\
1 / 4\end{array}$ \\
\hline $\begin{array}{l}\text { Akredit } \\
\text { asi } \\
\text { Prodi }\end{array}$ & $\begin{array}{l}13 \\
5\end{array}$ & 357 & 111 & $\begin{array}{l}1 / 4 \\
1 / 2 \\
1 / 1\end{array}$ \\
\hline $\begin{array}{l}\text { Letak } \\
\text { Prodi }\end{array}$ & $\begin{array}{l}24 \\
6\end{array}$ & 468 & 124 & $\begin{array}{l}11 \\
1\end{array}$ \\
\hline
\end{tabular}

Nilai sintesis fuzzynya

\begin{tabular}{|l|l|l|l|}
\hline & L & M & U \\
\hline S1 & 0.098 & 0.213 & 0.499 \\
\hline S2 & 0.031 & 0.050 & 0.100 \\
\hline S3 & 0.118 & 0.307 & 0.736 \\
\hline S4 & 0.180 & 0.421 & 0.998 \\
\hline
\end{tabular}

bobot sub kriteria profil prodi berturut turut sebagai berikut : 0.46, 0.32, 0.23, -0.02 ( Letak Prodi, Akreditasi Prodi, Lama Studi, Lulusan Dosen). d. Matriks perbandingan berpasangan antar sub kriteria Kegiatan Prodi

\begin{tabular}{|l|l|l|l|l|}
\hline & $\begin{array}{l}\text { Semi } \\
\text { nar }\end{array}$ & $\begin{array}{l}\text { Peng. } \\
\text { Masyar } \\
\text { akat }\end{array}$ & $\begin{array}{l}\text { Peneli } \\
\text { tian }\end{array}$ & $\begin{array}{l}\text { Field } \\
\text { trip }\end{array}$ \\
\hline $\begin{array}{l}\text { Semina } \\
\text { r }\end{array}$ & 111 & 357 & 357 & 246 \\
\hline $\begin{array}{l}\text { Peng. } \\
\text { Masyar } \\
\text { akat }\end{array}$ & $\begin{array}{l}1 / 7 \\
1 / 5\end{array}$ & 111 & 135 & 113 \\
\hline $\begin{array}{l}\text { Peneliti } \\
\text { an }\end{array}$ & $1 / 7$ & $1 / 51 / 3$ & 111 & $1 / 6$ \\
& $1 / 5$ & $1 / 1$ & & $1 / 4$ \\
$1 / 3$ & & $1 / 2$ \\
\hline $\begin{array}{l}\text { Fieldtri } \\
\mathrm{p}\end{array}$ & $1 / 6$ & $1 / 31 / 1$ & 246 & 111 \\
$1 / 4$ & $1 / 1$ & & \\
\hline
\end{tabular}

Nilai sintesis fuzzynya

\begin{tabular}{|l|l|l|l|}
\hline & L & M & U \\
\hline S1 & 0.216 & 0.531 & 1.225 \\
\hline S2 & 0.075 & 0.184 & 0.544 \\
\hline S3 & 0.036 & 0.063 & 0.165 \\
\hline S4 & 0.084 & 0.221 & 0.495 \\
\hline
\end{tabular}

bobot Sub Kriteria kegiatan prodi berturut turut sebagai berikut : 0.885, 0.066, 0.065, 0.06 ( Seminar, Pengabdian Masyarakat, Fieldtrip, Penelitian).

e. Matriks perbandingan berpasangan antar sub kriteria tata tertib

\begin{tabular}{|l|l|l|l|l|}
\hline & $\begin{array}{l}\text { Pakai } \\
\text { an }\end{array}$ & $\begin{array}{l}\text { Cu } \\
\text { ti }\end{array}$ & $\begin{array}{l}\text { NPM/ } \\
\text { NIM }\end{array}$ & $\begin{array}{l}\text { Perkulia } \\
\text { han }\end{array}$ \\
\hline Pakaian & 111 & 3 & $1 / 51 / 3$ & $1 / 41 / 2$ \\
& & 5 & $1 / 1$ & $1 / 1$ \\
7 & & \\
\hline Cuti & $1 / 7$ & 1 & $1 / 91 / 7$ & $1 / 81 / 6$ \\
& $1 / 5$ & 1 & $1 / 5$ & $1 / 4$ \\
& $1 / 3$ & 1 & & \\
\hline $\begin{array}{l}\text { NPM/N } \\
\text { IM }\end{array}$ & 135 & 5 & 111 & $1 / 61 / 4$ \\
& & 7 & & $1 / 2$ \\
\hline $\begin{array}{l}\text { Perkulia } \\
\text { han }\end{array}$ & 246 & 4 & 246 & 111 \\
& & 6 & & \\
& & & \\
\hline
\end{tabular}


Nilai sintesis fuzzynya

\begin{tabular}{|l|l|l|l|}
\hline & L & M & U \\
\hline S1 & 0.092 & 0.197 & 0.456 \\
\hline S2 & 0.028 & 0.043 & 0.081 \\
\hline S3 & 0.147 & 0.325 & 0.707 \\
\hline S4 & 0.186 & 0.433 & 0.958 \\
\hline
\end{tabular}

bobot Sub Kriteria tata tertib berturut turut sebagai berikut : $0.43,0.35,0.23,-0.03$ ( Perkuliahan, NPM/NIM, Pakaian, Cuti).

\section{Simpulan dan Saran}

Simpulan

Urutan perangkingan perhitungan fuzzy Analisis Hierarki Proses untuk faktor kriteria dan faktor sub kriteria pada penelitian ini sebagai berikut:

a. Faktor kriteria 0.582, 0.526, 0.055, 0.164 ( Profil Prodi, Sarana Prasarana, Kegiatan Prodi, Tata Tertib).

b. Faktor sub kriteria sarana prasarana 0.71, 0.40, 0.15, -0.27 ( Mutu Gedung Kuliah, Perpustakaan, Sarana Olah Raga, Laboratorium).

c. Faktor sub kriteria Profil Prodi 0.46, $0.32, \quad 0.23,-0.02$ ( Letak Prodi, Akreditasi Prodi, Lama Studi, Lulusan Dosen).

d. Faktor sub kriteria Kegiatan Prodi 0.885, 0.066, 0.065, 0.06 ( Seminar, Pengabdian Masyarakat, Fieldtrip, Penelitian).

e. Faktor sub kriteria Tata tertib 0.43 , $0.35, \quad 0.23,-0.03$ ( Perkuliahan, NPM/NIM, Pakaian, Cuti).

Saran

Peneliti berharap penelitian ini bisa menjadi bahan masukan / pemberi informasi terkait strategi pemasaran bagi pengelola Perguruan Tinggi Swasta khususnya di wilayah Kota Padangsidimpuan dalam hal memikat minat calon Mahasiswa untuk mendaftar pada Perguruan Tinggi yang dikelola oleh masing masing pihak pengelola Perguruan Tinggi Swasta di Kota Padangsidimpuan. Selain itu peneliti berharap penelitian ini bisa menjadi referensi bagi peneliti lain yang akan melakukan penelitian yang relevan dengan masalah dan metode yang digunakan pada penelitian ini. Selanjutnya kekurangan pada penelitian ini hendaknya dapat dikembangkan oleh peneliti selanjutnya.

\section{Ucapan Terima Kasih}

Tim peneliti mengucapkan terima kasih kepada Kemenristekdikti yang telah membantu pendanaan sehingga penelitian ini dapat terlaksana.

\section{Daftar Pustaka}

Saaty, T.L 1993. Pengambilan Keputusan Bagi Para Pemimpin, Proses Hirarki Analitik untuk Pengambilan Keputusan dalam Situasi yang Kompleks.Pustaka Binama Pressindo.

Saaty, T.L and Luis G. Vargas. 2006. Decision Making With The Analytic Network Process. Pittsburg, USA : University of Pittsburg.

Saaty, T.L. 2008. The seven pillars of the analytic hierarchy process. Pittsburg, USA: University of Pittsburgh.

Lu, J, Zang, G, Ruan, D \& Wu, F 2007, Multi Objective Group Decision Making: Methods, Software and Applications With Fuzzy Set Technique, Imperial College Press, London

Anshori yusuf, 2012, Pendekatan Triangular Fuzzy Number Dalam Metode Analytic Hierarchy Process, Jurnal Ilmiah Foristek Vol. 2, No. 1, Maret 2012

Chang, DY, 1996, “ Theory And Methodology: Applications of The Extent Analysis Method on Fuzzy AHP", European Journal Of Operational Research, vol 95, pp. $649-655$.

Dalalah Doraid, Al-Oqla Faris, Hayajneh Mohammed, (2010), Application of the Analytic Hierarchy Process (AHP) In Multi Criteria Analysis of the Selection of the Cranes, Jordan Journal of Mechanical and Industrial Engineering Volume 4 Number 5, November 2010

Setiawan Wahyudi, Pujiastutik Reny (2015) Penerapan Metode Fuzzy Analytical Hierarchy Process Untuk Pemilihan Supplier Batik Madura, jurnal.ftumj.ac.id/indekx.php/semnaste $\mathrm{k}$

Rouyendegh BD, Erkan T.E (2012) Selection of Academic Staff Using The Fuzzy Analytic Hierarchy Process, Technical Gazette 19, 4 (2012), 923 - 929 
Jurnal Karya Pendidikan Matematika Vol 5 No 2 (2018) E ISSN : 2549 - 8401 P ISSN : 2339-2444

Sari, Nurma Agus, Dkk. 2014 Sistem Pendukung Keputusan Pemilihan Analytical Hierarchy Process (AHP). Mahasiswa Berprestasi Menggunakan Metode Analytical Hierarchy Process $(A H P)$. Jurnal TIKomSiN

Adhi, Antono. 2010. Pengambilan Keputusan Pemilihan Handphone Terbaik Dengan Dinamika Teknik Vol. IV, No. 2. Suryano.2008.Metodelogi Penelitian kesehatan. Jogjakarta : Mitra Cendikia Press

Husein Umar. 2003, Riset Pemasatan dan Perilaku Konsumen, Gramedia Pustaka Pertama 